\title{
Analysis of Multilayer Conducdor Interconnects of Integrated Circuits
}

\author{
Lounas Belhimer, Mohamed Kessi \\ Faculty of Electrical Engineering and Computer Sciences \\ University Mouloud Mammeri, Tizi-Ouzou, Algeria \\ lounasbelhimer@yahoo.fr; Second.kessi_mohamed@hotmail.com
}

\begin{abstract}
The present paper deals with the analysis approach of multiconductor microstrip systems an integrated circuits using the finite element method (FEM). And we look for the best dimensions of the tracks for minimized the electromagnetic interaction in order to adapt them in microtechnology.

Interconnects are multiple strip and multilevel in ICs. Today interconnects are great attention in high speed digital design and microwave integrated circuit application. With increased density of packing, line to line coupling of electromagnetic also becomes prominent. Computation of the matrices of capacitances, inductances per unit length of multiconductor is important since these elements are essential parameters in designing of package.
\end{abstract}

Keywords: Interconnects, Finite Element Method, Capacitance, Multiconductor, Transmission Lines.

\section{Introduction}

Today the electronic circuits see their threshold of electromagnetic susceptibility decrease This increased vulnerability comes from their reduction in size in supply voltage and an increase in their frequency of operation the frequencies of the order of gigahertz are particularly harmful for these systems because by their wavelength they are likely to generate resonance phenomena on the tracks of the integrated circuits thus increasing the risks that it is disturbed.

Computation of the interconnect parameters such as matrices of capacitances and inductances per unit length is important since these parameters are essential in designing of package, lossless transmission line system and microwave circuits. Therefore, the improvement of accurate and efficient computational method to analyze the modeling of multiconductor structure becomes an important area of interest.

Transmission interconnect lines have been investigated for many years. In [1] Hassan ymeri presented a new semianalytical procedure for single and coupled interconnects on lossy silicon substrate. In [2] starting from several reasonable approximations, closed-from expression for the mutual impedance per unit length of coupled IC interconnects with silicon substrate have be proposed. [3], analysis of multiconductor quasi-TEM transmission lines and multimode waveguide is done. We can mention, the spectral- domain analysis method [4], variational technique [5], the method of moment [6], the Galerkin method [7].

In this paper, we design four-conductor transmission lines interconnect with two dielectric layers, and four-conductor transmission line with two levels systems using FEM to calculate the capacitance matrix then compare the results with some methods in previous publications.

\section{Main Results}

The capacitance coefficients for a system of paralle microstrip lines are defined as follows; it is convenient to write [89]:

$$
Q_{i}=\sum_{j=1}^{n} C_{s i j} V_{j}
$$


Where $V_{j}$ is the voltage of $j$ th conductor with reference to the ground plane, $\mathrm{Q}_{\mathrm{i}}$ is the charge per unit length, $\mathrm{C}_{\mathrm{sij}}$ is the short circuit capacitance between $i$ th and $j$ th conductor. The short circuit capacitances can be obtained either from measurement or from numerical computation [10-11]. We obtain

$$
\begin{gathered}
C_{i i}=\sum_{j=1}^{n} C_{s i j} \\
C_{i i}=-C_{s i j}, \mathrm{i} \neq \mathrm{j}
\end{gathered}
$$

Where $\mathrm{C}_{\mathrm{ii}}$ is the capacitance per unit length between the $i$ th conductor and the ground plane. The inductance and capacitance of multiconductor transmission lines are related as

$$
[L]=\mu_{0} \varepsilon_{0}\left[C_{0}\right]^{-1}
$$

Where,

$[\mathrm{L}]=$ Inductance matrix.

$[\mathrm{C}]^{-1}=$ the inverse matrix of the capacitance of multiconductor transmission line when all dielectric constants are set equal to 1 .

$\mu_{0}=$ permeability of space or vacuum.

$\varepsilon_{0}=$ permittivity of free space or vacuum.

The characteristic impedance and capacitance per unit length are related as follows:

$$
Z=\sqrt{\frac{[L]}{[C]}}
$$

The electrical parameters are:

Capacitance per unit length matrix ([C] in $\mathrm{pF} / \mathrm{m}$ ), inductance per unit length ([L] in $\mathrm{nH} / \mathrm{m}$ ), impedance ([Z] in $\Omega$ ).

To illustrate and validate the new proposed formulation, in the first section we consider a planar interconnects line including four strips, Fig. 1. shows the geometry of the model.

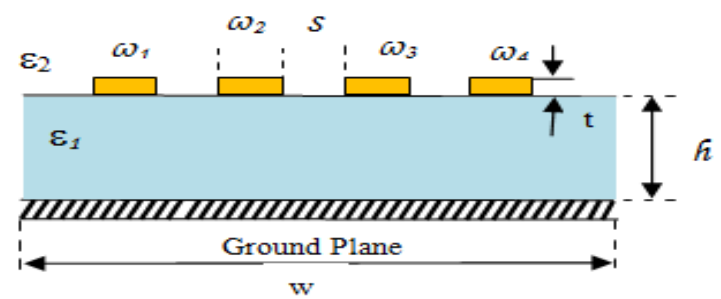

Fig. 1: Symmetric microstrip coupled interconnect.

This microstrip coupled interconnects have the following geometrical parameters:

- $\omega_{1}=\omega_{2}=\omega_{3}=\omega_{4}=20 \mu \mathrm{m}, \mathrm{S}=20 \mu \mathrm{m}, \mathrm{h}=40 \mu \mathrm{m} \quad \mathrm{t}=5 \mu \mathrm{m}, \varepsilon_{1}=11.7, \varepsilon_{2}=3.9$ 


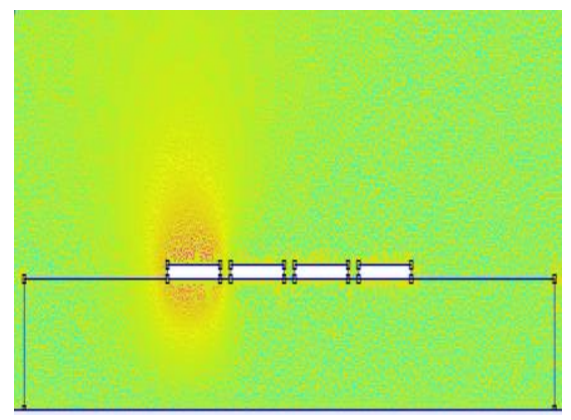

Fig. 2: Mesh of four strip conductor system.

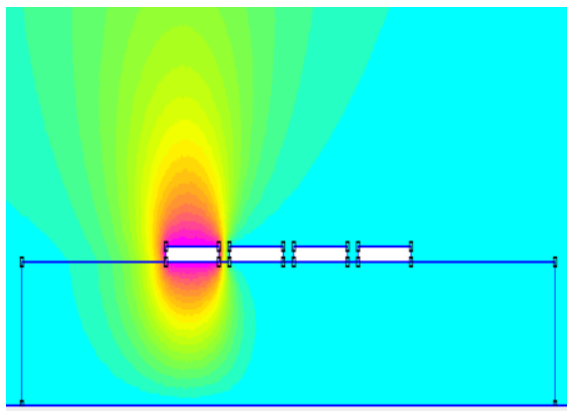

Fig. 3: Surface potential distribution of four strip conductors system.

The capacitance and inductance per unit length of the multistrip transmission lines are related as follows:

$$
C=\left[\begin{array}{cccc}
0.968 & -0.328 & -0.08 & -0.01 \\
-0.328 & 1.126 & -0.325 & -0.08 \\
-0.08 & -0.325 & 1.126 & -0.328 \\
-0.01 & -0.08 & -0.328 & 0.968
\end{array}\right]
$$$$
L=\left[\begin{array}{llll}
0.1063 & 0.0381 & 0.0220 & 0.0117 \\
0.0381 & 0.1025 & 0.0387 & 0.0219 \\
0.0220 & 0.0387 & 0.1025 & 0.0381 \\
0.0117 & 0.0219 & 0.0381 & 0.1062
\end{array}\right]
$$

Table 1 shows the FEM results for the self capacitance per unit length of the fourth conductor transmission lines interconnect with two dielectric layer. They are compared with Galerkin method and parallel lines propagation TEM waves method. They are not too close.

Table 1: Capacitance matrix of the model in figure 1.

\begin{tabular}{|c|l|l|}
\hline $\begin{array}{c}\text { Capacitance } \\
\left(10^{-10} \mathrm{~F} / \mathrm{m}\right)\end{array}$ & $\begin{array}{l}\text { Galerkin } \\
\text { method }\end{array}$ & $\begin{array}{c}\text { Our } \\
\text { work }\end{array}$ \\
\hline $\mathrm{C}_{11}$ & 0.475 & 0.968 \\
\hline $\mathrm{C}_{12}$ & -0.582 & -0.328 \\
\hline $\mathrm{C}_{13}$ & -0.114 & -0.08 \\
\hline $\mathrm{C}_{14}$ & -0.062 & -0.01 \\
\hline $\mathrm{C}_{22}$ & 0.289 & 1.112 \\
\hline
\end{tabular}

The calculation of the matrix $[\mathrm{C}]$ for the given cut rst made by making varies some parameters.

The parameters studied are:

$\mathrm{t}$, thickness of the track varying from 5 to $10 \mu \mathrm{m}$ 
$\mathrm{h}$, height of the oxide, ranging from 40 to $100 \mu \mathrm{m}$

Six cases were simulated; the table below shows the values of the parameters.

Table 2: Simulated case parameter values of interconnect.

\begin{tabular}{|l|l|l|l|l|l|}
\hline \multicolumn{1}{|c|}{ Case1 } & \multicolumn{1}{|c|}{ Case2 } & \multicolumn{1}{c|}{ Case3 } & \multicolumn{1}{c|}{ Case4 } & \multicolumn{1}{c|}{ Case5 } & \multicolumn{1}{c|}{} \\
\hline $\mathrm{W}=\mathrm{S}=20 \mu \mathrm{m}$ & $\mathrm{W}=\mathrm{S}=20 \mu \mathrm{m}$ & $\mathrm{W}=\mathrm{S}=20 \mu \mathrm{m}$ & $\mathrm{W}=\mathrm{S}=20 \mu \mathrm{m}$ & $\mathrm{W}=\mathrm{S}=20 \mu \mathrm{m}$ & $\mathrm{W}=\mathrm{S}=20 \mu \mathrm{m}$ \\
$\mathrm{t}=5 \mu \mathrm{m}$ & $\mathrm{t}=10 \mu \mathrm{m}$ & $\mathrm{t}=5 \mu \mathrm{m}$ & $\mathrm{t}=10 \mu \mathrm{m}$ & $\mathrm{t}=5 \mu \mathrm{m}$ & $\mathrm{t}=1 \mu \mathrm{m}$ \\
$\mathrm{h}=40 \mu \mathrm{m}$ & $\mathrm{h}=40 \mu \mathrm{m}$ & $\mathrm{h}=80 \mu \mathrm{m}$ & $\mathrm{h}=80 \mu \mathrm{m}$ & $\mathrm{h}=100 \mu \mathrm{m}$ & $\mathrm{h}=100 \mu \mathrm{m}$ \\
\hline
\end{tabular}

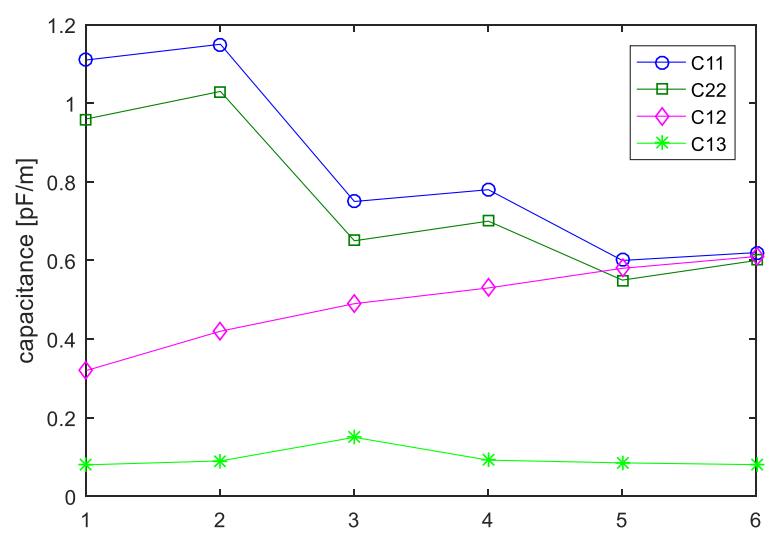

Fig. 4: Capacitance per unit length.

A general analysis makes it possible to notice that the capacitances towards the mass, C11 and C22 decrease with the increase of the distance h, with respect to the plane of mass. At the same time, the $\mathrm{C} 12$ and $\mathrm{C} 13$ capacities vary in phase, with the increase in h.on finding that the wider the track, the greater the parasitic coupling between the lines.

In the second section we consider a planar interconnects line including nine strips with four levels systems, Fig. 2. shows the geometry of the model. We will vary the parameters (w, s, t, h), we calculate the matrices [C], [L], [Z].

Table 3: Simulated case parameter values of interconnect.

\begin{tabular}{|l|l|l|l|l|l|}
\hline \multicolumn{1}{|c|}{ Case1 } & \multicolumn{1}{|c|}{ Case2 } & \multicolumn{1}{c|}{ Case3 } & Case4 & \multicolumn{1}{c|}{ Case5 } & \multicolumn{1}{c|}{ Case6 } \\
\hline $\mathrm{W}=\mathrm{S}=20 \mu \mathrm{m}$ & $\mathrm{W}=\mathrm{S}=20 \mu \mathrm{m}$ & $\mathrm{W}=\mathrm{S}=20 \mu \mathrm{m}$ & $\mathrm{W}=\mathrm{S}=20 \mu \mathrm{m}$ & $\mathrm{W}=\mathrm{S}=20 \mu \mathrm{m}$ & $\mathrm{W}=\mathrm{S}=20 \mu \mathrm{m}$ \\
$\mathrm{t}=5 \mu \mathrm{m}$ & $\mathrm{t}=10 \mu \mathrm{m}$ & $\mathrm{t}=5 \mu \mathrm{m}$ & $\mathrm{t}=10 \mu \mathrm{m}$ & $\mathrm{t}=5 \mu \mathrm{m}$ & $\mathrm{t}=1 \mu \mathrm{m}$ \\
$\mathrm{h}=40 \mu \mathrm{m}$ & $\mathrm{h}=40 \mu \mathrm{m}$ & $\mathrm{h}=80 \mu \mathrm{m}$ & $\mathrm{h}=80 \mu \mathrm{m}$ & $\mathrm{h}=100 \mu \mathrm{m}$ & $\mathrm{h}=100 \mu \mathrm{m}$ \\
\hline
\end{tabular}




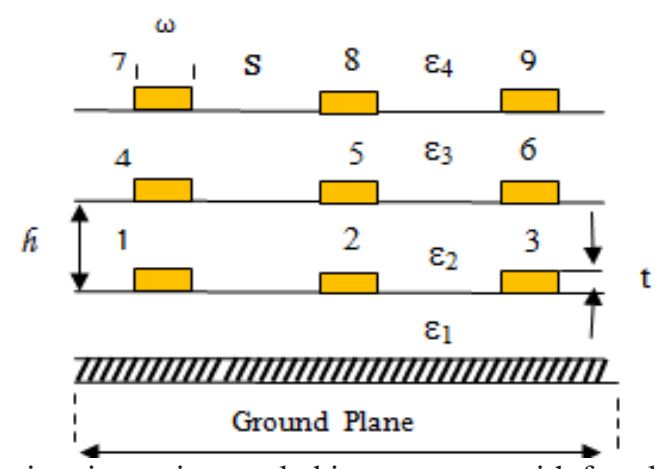

Fig. 5: Symmetric microstrip coupled interconnect with four levels systems.

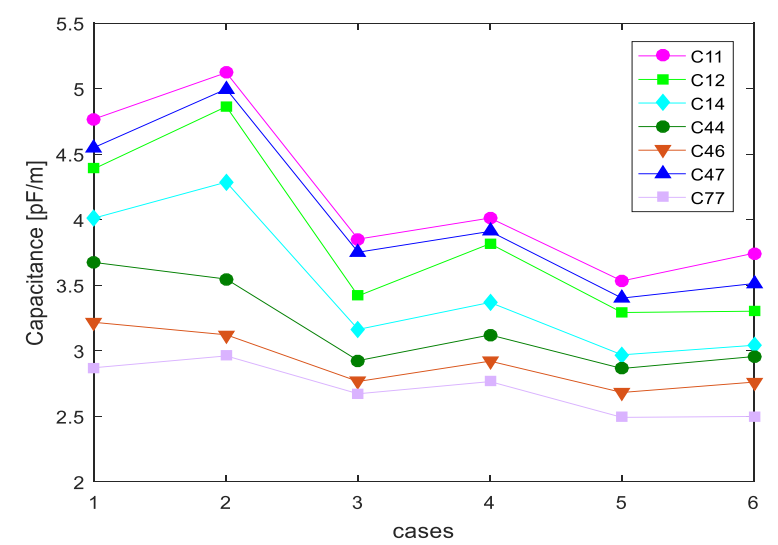

Fig. 6: Capacitance versus geometry of track.

A general analysis makes it possible to notice that the capacitances towards the mass, $\mathrm{C} 11 ; \mathrm{C} 44$ and $\mathrm{C} 77$ decrease with the increase of the distance h, with respect to the plane of mass. At the same time, the $\mathrm{C} 12$ and $\mathrm{C} 14$ capacities vary in phase, with the increase in $\mathrm{h}$. on finding that the wider the track, the greater the parasitic coupling between the lines

In the third part we add a ground plane located at $4 \mathrm{~h}$ of foreground of mass, then we vary the parameters (w, s, t, h), we calculate the matrices [C], [L], [Z]. And we compare the results obtained with those of the first part.
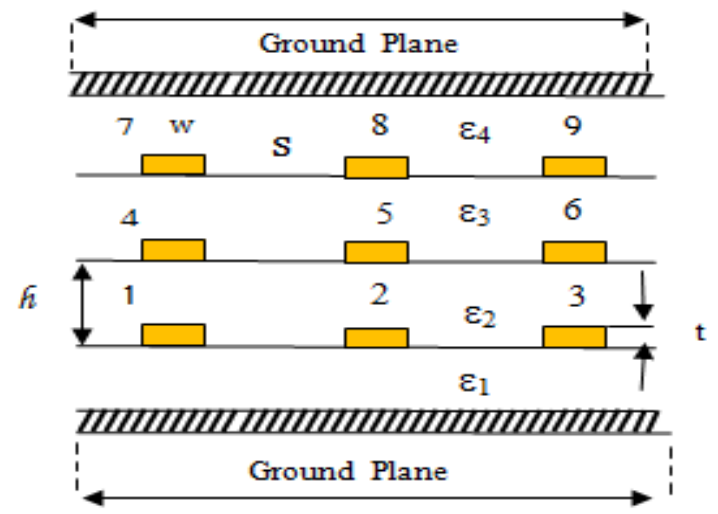

Fig. 7: Symmetric microstrip coupled interconnect with four levels systems with two ground plane. 


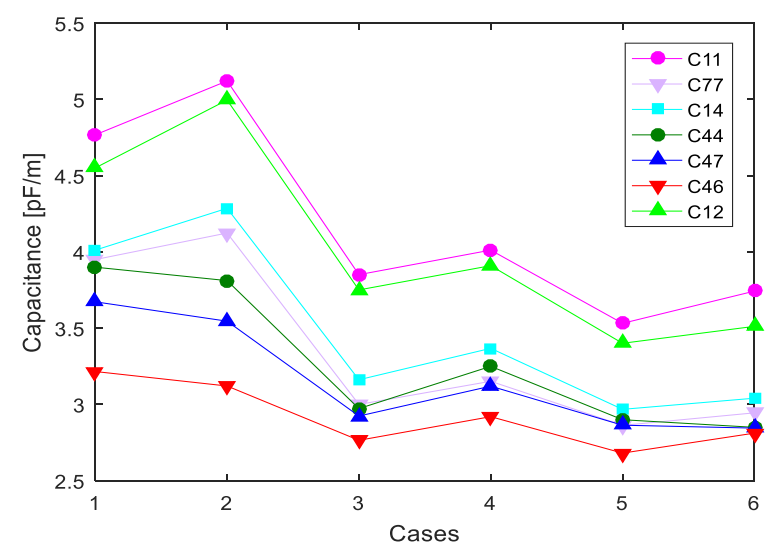

Fig. 8: Capacitance versus geometry of track.

\section{Conclusion}

In this paper we have identified the potential distributor for four interconnect transmission lines and we computed the capacitance matrix. And we noticed that more the track is large the parasitic coupling between the lines is more important. The results obtained in this research to comply with literature and motivating for the future study.

\section{References}

[1] H. Ymeri, B. Nauwelaers, K. Maex, D. De Roest, and Vandenberghe, "Admittance matrix calculations of on-chip interconnects on lossy silicon substrate using multilayer green's function," IEEE cat. No. 01EX496, pp. 7803-7129, 2001.

[2] H. Ymeri, B. Nauwelaers, K. Maex, Vandenber,and D. De Roest, and Vandenber, "New analytic expression for mutual inductance and ressistance of coupled interconnects on lossy silicon substrate," IEEE cat. No. 01EX496, pp. 7803-7129, 2001.

[3] S. M. Musa, M. N. O. Sadiku, and K. T. Harris, "Modeling of multiconductor microstrip systems on microwave integrated circuits," Comsol conference in boston, 2013.

[4] T. C. Mu, H. Orgawa and T. Itoh, "characteristics of multiconductor, asymmetric, slow-wave microstrip transmission lines," IEEE transmission on microwave theory techniques, vol. MTT-34, pp. 1471-1477, 1986.

[5] F. Medina and M. Horno, "Capacitance and inductance matrices for multistrip structures in multilayered anisotropic," IEEE Transmission on microwave theory and techniques, vol. 35, no. 11, pp. 1002-1008, 1987.

[6] C. Wei, R. F. Harrigton, J. R. Mautz, and T. K. Sarkar, "Multiconductor transmission lines in multilayered dielectric media," IEEE transmissions on microwave theory and techniques, vol. 32, no. 4, pp. 439-45, 1984.

[7] H. Ymeri, B. Nauwelaers, K. Maex, and D. De Roest, "A new approach for the calculation of line capacitances of two-layer IC interconnects," Microwave and Optical Technology Letters, vol. 27, no. 5, pp. 297-302, 2000.

[8] M. S. Lin, "Meseared capacitance coefficients of multiconductor microstrip lines with small dimensions," IEEE transactions on microwave Theory and Techniques, vol. 13, no. 4, pp. 1050-1054, 1990.

[9] F. Y. Chang, "Transient analysis of lossless coupled transmission lines in a nonhomogeneous dielectric media," IEEE transactions on microwave Theory and Techniques, vol. 18, no. 9, pp. 616-626, 1970.

[10] Z. Q. Ning. P. M. Dewilde, and F. L. Neerhoff, "Capacitance coefficients for VLSI multilevel metallization lines," IEEE trans.Electro. Devices, vol. ED-34, p. 644, 1987.

[11] C. D. Taylor, G. N. Elkhori, and T. E. Wade, "On the parasitic capacitances of multilevel parallel metallization lines," IEEE trans. Electro. Devices, vol. ED-32, p. 2408. 1987. 